\title{
Kajian Daya Dukung Fisik Wisata Berkemah Telaga Cebong Desa Sembun- gan untuk Mendukung Pariwisata Berkelanjutan
}

\author{
Sri Rahayu Budiani ${ }^{1}$, Lucky Puspitasari ${ }^{2}$, Masna Naila Adibah ${ }^{3}$, Sandra Nisa Basuki ${ }^{4}$ dan Atik Fauzia ${ }^{5}$
}

1,2,3,4,5 Fakultas Geografi, Universitas Gadjah Mada, Indonesia

Email koresponden: srahayu@ugm.ac.id

Diterima: 2018-01-15 /Refisi:2018-05-24 Disetujui:2019-03-04

(๑2019 Fakultas Geografi UGM dan Ikatan Geograf Indonesia (IGI)

\begin{abstract}
Abstrak Aktivitas pariwisata berkemah di Telaga Cebong menunjukkan peningkatan yang dapat berpengaruh terhadap lingkungan. Penelitian ini bertujuan untuk menghitung daya dukung lingkungan fisik Telaga dan merekomendasikan strategi optimalisasi objek wisata Telaga Cebong berdasarkan asas pariwisata berkelanjutan. Penelitian ini menggunakan rumus Physical Carrying Capacity (PCC) untuk menghitung daya dukung lingkungan fisik dengan menggunakan variabel luas wilayah wisata, luas wilayah agar wisatawan tetap merasa nyaman, dan faktor rotasi. Hasil penelitian menunjukkan bahwa nilai daya dukung lingkungan fisik Telaga Cebong adalah 404 tenda per hari atau 1.615 orang per hari. Jumlah wisatawan yang berkemah baik saat hari kerja maupun akhir pekan belum melampaui nilai daya dukung sehingga perlu adanya perbaikan sarana prasarana, meningkatkan tingkat kebersihan, pengelolaan sampah yang baik, penambahan kegiatan yang dapat memberikan daya tarik kepada pengunjung, penataan ruang, penambahan tempat untuk berfoto, pengembangan atraksi wisata, dan pengembangan fasilitas wisata telaga, misalnya perahu, boat, serta
\end{abstract}

Kata kunci: pariwisata, wisata berkemah, daya dukung fisik, Dieng

Abstract Camping tourism activities in Cebong Lake show an increase that can affect the environment. This study aims to calculate the carrying capacity of Telaga's physical environment and recommend strategies to optimize the tourism object of Telaga Cebong based on the principle of sustainable tourism. This study uses the formula of Physical Carrying Capacity (PCC) to calculate the carrying capacity of the physical environment by using a variable area of tourist area, area area so that tourists still feel comfortable, and rotation factors. The results showed that the value of carrying capacity of the physical environment of Telaga Cebong was 404 tents per day or 1,615 people per day. The number of tourists camping both on weekdays and weekends has not exceeded the value of carrying capacity so there is a need to improve infrastructure, increase the level of cleanliness, good waste management, adding activities that can attract visitors, spatial planning, adding photos, development of tourist attractions, and development of lake tourism facilities, such as boats, boats and flying fox.

Keywords: tourism, Camping tour, Physical Carrying Capacity, Dieng

\section{PENDAHULUAN}

Menurut Holloway dan Plant (1989) dalam Yulianda (2007), pariwisata adalah kegiatan perpindahan untuk memperoleh kenikmatan dalam perjalanan atau di tempat tujuan, sedangkan wisata ialah pemanfaatan sumberdaya alam yang mengandalkan jasa alam untuk mendapatkan kepuasan manusia. Pariwisata memiliki peran yang besar dalam pembangunan nasional karena selain menghasilkan pendapatan dan sebagai penghasil devisa, sektor pariwisata pun berkaitan erat dengan penanaman modal asing (Rani, 2014). Sektor pariwisata juga berpotensi mendorong pertumbuhan sektor swasta dan pembangunan infrastruktur serta peningkatan penerimaan negara dari pajak, terutama pajak tidak langsung (Nizar, 2011). Sektor pariwisata telah dijadikan sebagai sektor unggulan oleh banyak negara, misalnya Kepulauan Karibia dan negaranegara di kawasan Pasifik (Pitana, 2005). Indonesia merupakan negara yang penuh dengan keindahan alam karena negara ini memiliki berbagai macam bentangalamsehingga memiliki potensi wisata yang perlu dikelola dengan baik oleh warga Indonesia.
Kawasan dataran tinggi Dieng yang terletak pada ketinggian $2.093 \mathrm{mdpl}$ dengan suhu rata-rata 10-20冈C (Irhamna, 2017) merupakan salah satu wilayah tujuan wisata yang berada di Kabupaten Wonosobo, Jawa Tengah. Dieng memiliki peninggalan sejarah yang menjadi daya tarik wisatawan, yaitu kompleks candi Diengyang dibangun pada masa Kerajaan Hindu dengan luas $900.000 \mathrm{~m} 2$ (Raharja, 2012). Wisata budaya lainnya yang tak kalah menarik adalah tradisi ritual rambut gembel (gimbal) yang menjadi daya tarik bagi wisatawan (Soehadha, 2013). Dieng memiliki bentangalam khas, yaitu terdapat banyak kawah dan telaga yang dijumpai di kawasan wisata Dieng (Susilawati dkk, 2013). Salah satu wisata alam yang menarik di kawasan dataran tinggi Dieng adalah wisata di Desa Sembungan. Objek wisata di Desa Sembungan yang sangat terkenal adalah objek wisata pendakian Puncak Sikunir yang pada tahun 2017 dikunjungi oleh 131.700 pengunjung (Pokdarwis Cebong-Sikunir, 2017 dalam Pamungkas, 2017). Telaga Cebong merupakan multiplier effect dari wisata pendakian Puncak Sikunir. Telaga Cebong sengaja dijadikan sebagai tempat singgah 
untuk berkemah dan bermalam menunggu matahari terbit. Ketika matahari akan terbit, maka wisatawan meninggalkan kemahnya dan mendaki Bukit Sikunir. Namun demikian, wisatawan yang berkunjung ke Desa Sembungan tidak hanya berkunjung ke Sikunir saja, tetapi ada pula yang sengaja mengunjungi Telaga Cebong untuk berkemah (Gambar 1).

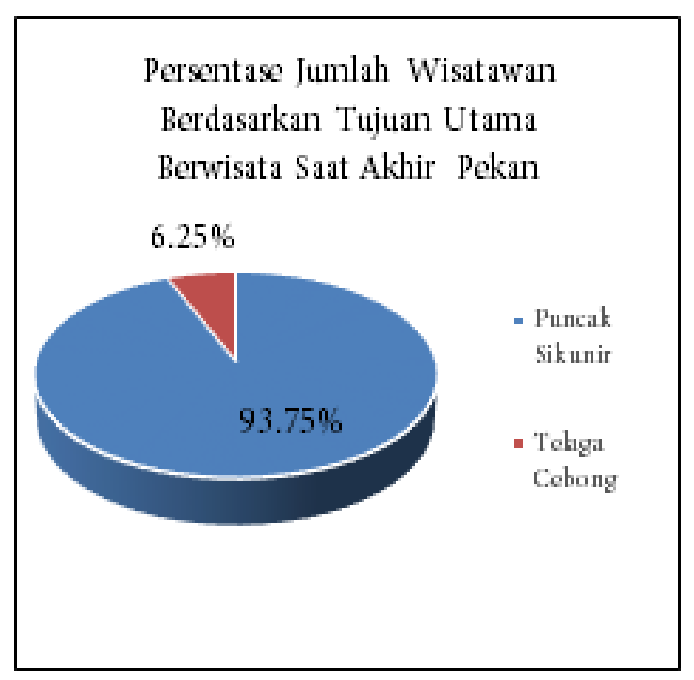

Gambar 1. Diagram Persentase Jumlah Wisatawan Berdasarkan Tujuan Utama Berwisata Saat Akhir Pekan (Hasil Olah Data Penulis, 2017)
Jumlah wisatawan yang sangat banyak di Desa Sembungan sering menyebabkan wisatawan tidak dapat bermalam di homestay karena kehabisan kamar (Tribun, 2017). Telaga Cebong dapat dijadikan sebagai alternatif untuk bermalam di Desa Sembungan. Jumlah wisatawan yang berkemah di Telaga Cebong semakin banyak. Hal tersebut dapat menimbulkan aktivitas wisata di wilayah tersebut menjadi meningkat. Peningkatan aktivitas pariwisata akan berpengaruh terhadap ekosistem lingkungan, bahkan dapat merusak lingkungan tersebut. Selain itu, tingkat kenyamanan wisatawan juga akan berkurang apabila terjadi kepadatan yang tinggi (Gunn, 1994). Hal tersebut sangat terkait dengan daya dukung lingkungan dari objek wisata yang dikunjungi. Daya dukung lingkungan dalam konteks ekologis merupakan jumlah populasi yang mampu didukung oleh sumberdaya yang ada pada suatu lingkungan tertentu (Rees, 1990). Menurut Greymore (2005), daya dukung lingkungan adalah jumlah maksimum manusia yang mampu didukung oleh bumi dan sumberdaya alam yang tersedia di dalamnya. Daya dukung lingkungan objek wisata alam merupakan kemampuan atau kapabilitas suatu wilayah untuk menerima pengunjung wisata yang dinyatakan dalam jumlah wisatawan per satuan luas per satuan waktu (Soemarwoto, 2004), sedangkan daya dukung fisik (Physical Carrying

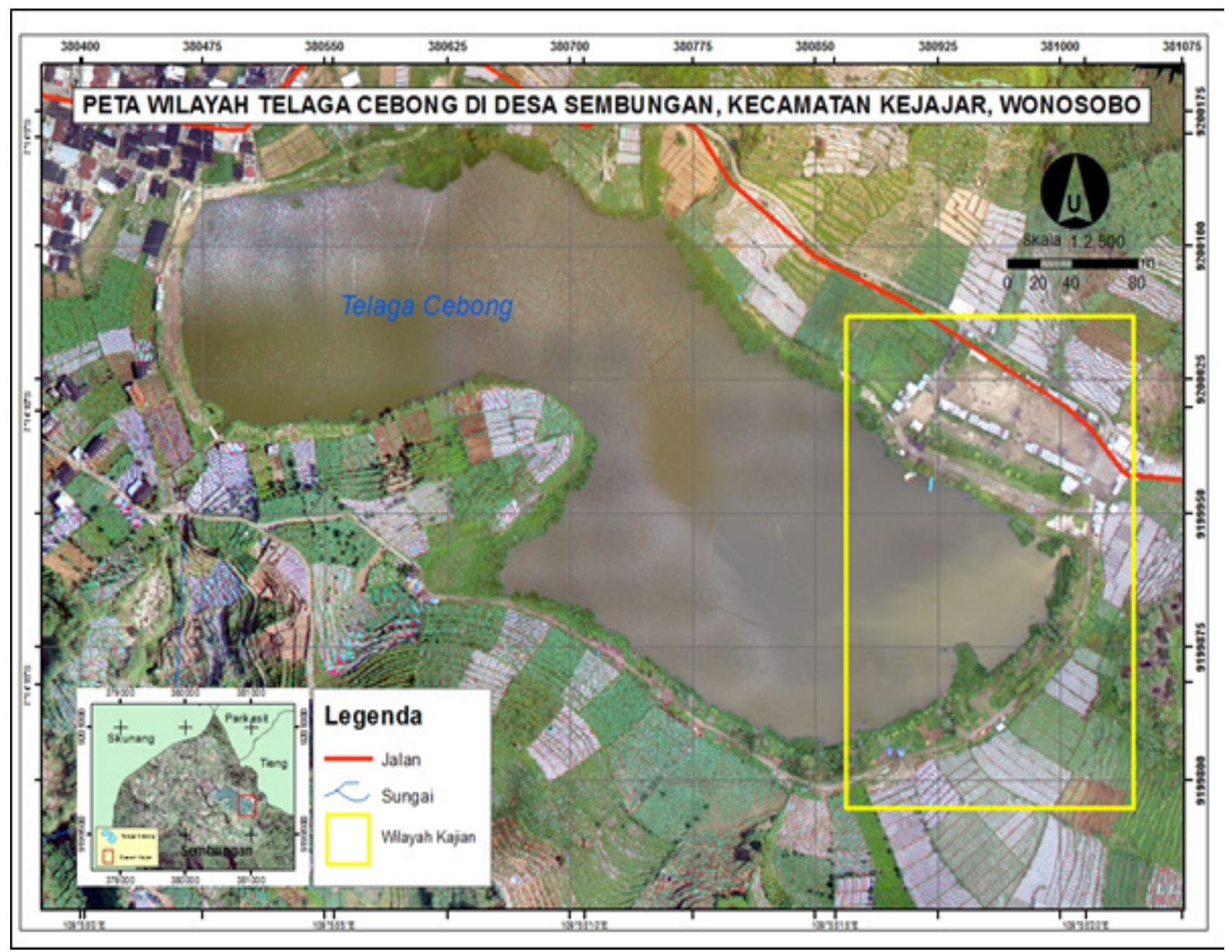

Gambar 2. Wilayah Kajian (Pengolahan Foto Udara, 2017) 
Capacity/PCC) merupakan jumlah maksimum wisatawan yang secara fisik tercukupi oleh ruang yang disediakan pada waktu tertentu (Purwanto dkk., 2014). Perhitungan nilai PCC dilakukan sebagai upaya untuk mewujudkan pariwisata yang berkelanjutan yang fokus pada kelestarian lingkungan. Pariwisata berkelanjutan secara sederhana merupakan pariwisata yang memperhitungkan penuh dampak ekonomi, sosial dan lingkungan saat ini dan masa depan, memenuhi kebutuhan pengunjung, industri, lingkungan dan masyarakat setempat (UN World Tourism Organization (UNWTO), 2013). Oleh sebab itu, perlu dikaji daya dukung fisik di wilayah tersebut. Tujuan penelitian ini adalah untuk mengetahui nilai daya dukung fisik (PCC) kawasan Telaga Cebong sebagai area perkemahan dan merekomendasikan strategi optimalisasi objek wisata Telaga Cebong berdasarkan asas pariwisata berkelanjutan.

\section{METODE PENELITIAN}

\section{Wilayah Kajian}

Wilayah kajian penelitian ini adalah kawasan wisata berkemah Telaga Cebong (Gambar 2). Penelitian dilakukan pada hari kerja (weekday) dan akhir pekan (weekend). Telaga Cebong terletak di Desa Sembungan, Kecamatan Kejajar, Kabupaten Wonosobo, Provinsi Jawa Tengah. Kawasan berkemah Telaga Cebong terletak pada wilayah yang cenderung datar sehingga dapat dimanfaatkan untuk berkemah.

Telaga Cebong memiliki pemandangan alam yang indah (Gambar 3). Wilayah sekitar Telaga Cebong dapat digunakan untuk kegiatan camping bagi wisatawan (Gambar 4).

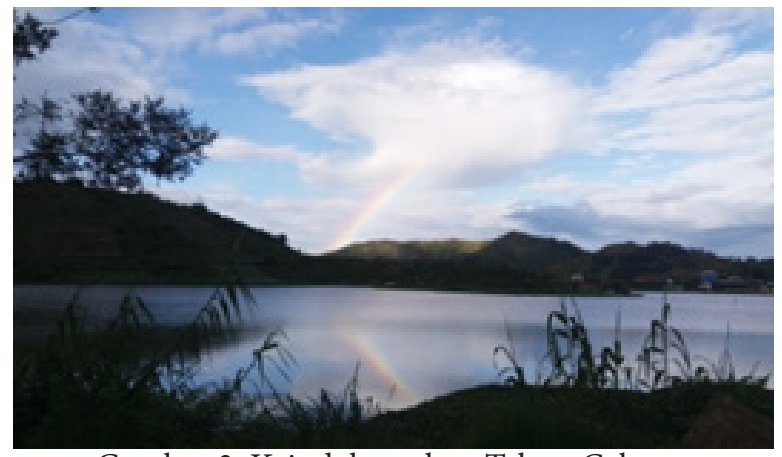

Gambar 3. Keindahan alam Telaga Cebong

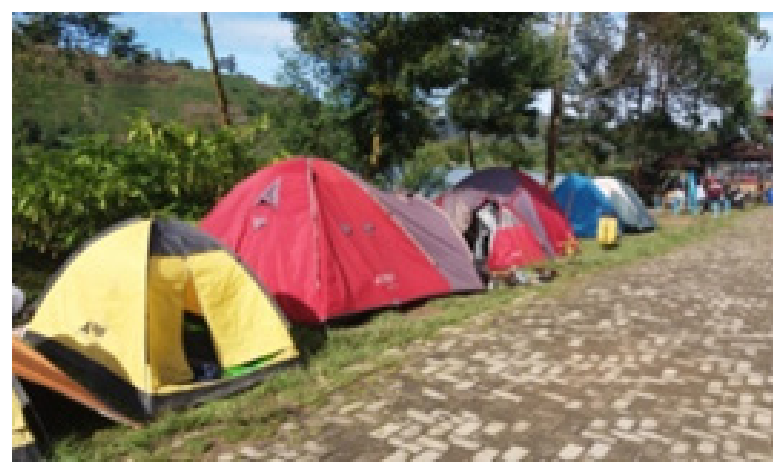

Gambar 4. Kegiatan camping di Telaga Cebong

\section{Pengumpulan Data}

Data yang dikumpulkan dalam penelitian ini adalah data luas wilayah wisata, data luas wilayah tenda agar wisatawan tetap berkemah dengan nyaman, data durasi waktu yang disediakan oleh pengelola kawasan wisata untuk kegiatan wisata, dan data rata-rata durasi kunjungan pengunjung. Data tersebut dikumpulkan dengan cara sebagai berikut.

\section{Foto Udara}

Foto udara dipotret menggunakan drone. Foto ini didelineasi untuk mendapatkan luas wilayah wisata kawasan Telaga Cebong.

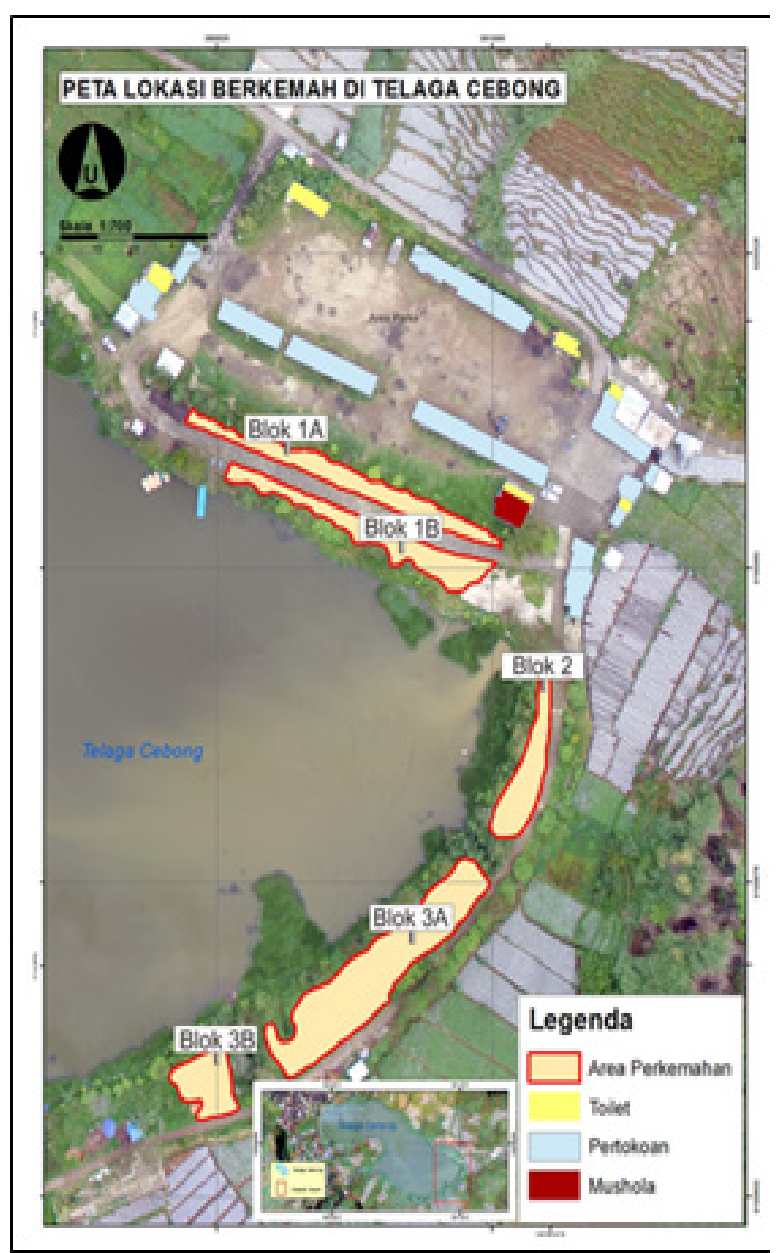

Gambar 5. Peta Lokasi Berkemah di Telaga Cebong (Hasil Pengolahan Foto Udara, 2017)

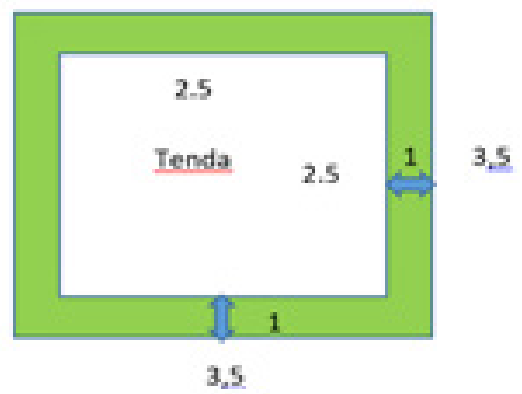

Gambar 6. Ilustrasi luas kenyamanan wisatawan dalam mendirikan tenda 


\section{Wawancara}

Wawancara dilakukan terhadap seluruh wisatawan yang berkemah dan/atau menikmati pemandangan di kawasan Telaga Cebong pada saat penelitian. Anggota populasi tidak dapat ditentukan secara pasti karena wisatawan yang datang ke Telaga Cebong tidak sama setiap hari, maka anggota populasi juga dianggap sebagai anggota sampel. Oleh sebab itu, pengumpulan data diperoleh dengan cara wawancara secara accidental. Data yang diperoleh berupa luas wilayah agar wisatawan tetap merasa nyaman dan ratarata durasi kunjungan pengunjung ke lokasi tersebut.

\section{Wawancara mendalam}

Wawancara mendalam dilakukan terhadap pengelola wisata kawasan Telaga Cebong untuk memperoleh data yang disediakan oleh pengelola kawasan wisata untuk kegiatan wisata.

\section{Analisis Data}

Penelitian ini menggunakan teknik analisis data deskriptif komparatif. Jenis analisis data tersebut digunakan untuk membandingkan jumlah pengunjung di lapangan dengan daya dukung fisik lingkungan ideal berdasarkan perhitungan. Penilaian daya dukung fisik lingkungan ideal dapat menerapkan perhitungan daya dukung yang dikembangkan oleh Cifientes (1992). Perhitungan dengan metode ini memperhatikan beberapa faktor penting antara lain luas area wisata, luas area yang dibutuhkan oleh wisatawan untuk bergerak bebas, dan aliran wisatawan (tourist flows), yang dapat diperoleh dengan cara pengamatan lapangan, wawancara, dan studi literatur(Lucyanti, 2013). Analisis dilakukan untuk mengetahui daya dukung fisik lingkungan di Telaga Cebong sudah sesuai atau melebihi daya dukung ideal berdasarkan perhitungan daya dukung fisik sebagai berikut.

\section{Foto Udara}

Foto udara diproses secara fotogrametri menjadi mozaik foto, sehingga dapat ditampilkan kawasan wisata Telaga Cebong secara jelas. Perhitungan luas wilayah Telaga Cebong dilakukan dengan mendelineasi foto udara tersebut menggunakan perangkat lunak ArcGIS.

\section{Luas Wilayah Tenda Agar Wisatawan Tetap Berkemah dengan Nyaman}

Luas yang dibutuhkan wisatawan untuk merasa nyaman yaitu berdasarkan asumsi kapasitas ukuran luas tenda untuk menampung jumlah orang. Selain itu, kenyamanan pengunjung juga diperhitungkan dari jarak tenda dengan tenda lainnya.

\section{Faktor Rotasi}

Faktor rotasi merupakanwaktu yang disediakan oleh pengelola kawasan wisata untuk kegiatan wisata dibandingkan dengan rata-rata durasi kunjungan pengunjung.

\section{Perhitungan PCC}

Perhitungan daya dukung fisik (PCC) kawasan wisata Puncak Sikuniapat dilakukan dengan menggunakan rumus berdasarkan metode yang dikembangkan oleh Fandeli dan Muhammad (2009) yaitu yang tertera pada persamaan (1).

$\mathrm{PCC}=\mathrm{A} \times 1 / \mathrm{B} \times \mathrm{Rf}$

\section{Keterangan:}

$\mathrm{A}=$ luas wilayah wisata

$\mathrm{B}=$ luas wilayah wisata yang diperlukan wisatawan

agar tetap merasa nyaman

$\mathrm{Rf}=$ faktor rotasi (waktu yang disediakan oleh

pengelola kawasan wisata untuk kegiatan wisata dibagi dengan rata-rata durasi kunjungan)

\section{HASIL DAN PEMBAHASAN \\ Kondisi Umum Lokasi}

Telaga Cebong terbentukakibat dariadanya aktivitas vulkanik, yaitu bekas dari kawah purba. Telaga Cebong terletak di sebelah barat Gunung Sikunir. Luas Telaga Cebong yaitu 18 ha, tetapi sekarang sudah berkurang menjadi 12 ha (Sudarmadji, Supriyono, \& Lestari, 2015). Sumber daya alam yang dapat dikembangkan menjadi atraksi wisata alam adalah: (1) keajaiban dan keindahan alam (topografi), (2) keragaman flora, (3) keragaman fauna, (4) kehidupan satwa liar, (5)vegetasi alam, (6) ekosistem yang belum terjamah manusia, (7) rekreasi perairan (danau, sungai, air terjun, pantai), (8) lintas alam (trekking, rafting, dan lain-lain), (9) objek megalitik, (10) suhu dan kelembaban udara yang nyaman, (11) curah hujan yang normal, dan lain sebagainya (Damanik, Janianton, \& Weber, 2006) dalam (Machdalena, Dewi, \& Soemantri, 2018). Berdasarkan pengembangan sumber daya alamnya, Telaga Cebong merupakan rekreasi perairan (danau) sekaligus keidahan alam. Menurut Rinaldi (2015) kegiatan perkemahan dilakukan pada wilayah dengan kontur yang relatif datar. Kawasan Telaga Cebong mempunyai topografi datar sehingga cocok untuk lokasi berkemah. Luas wilayah yang digunakan untuk kegiatan berkemah di Telaga Cebong berdasarkan hasil delineasi foto udara adalah 2.060,72 $\mathrm{m} 2$. Luas tersebut dibagi ke dalam lima blok perkemahan, yaitu Blok 1A, 1B, 2, 3A, dan3B (Gambar 5). Daya Dukung Fisik Telaga Cebong Wisatawan yang berkemah di Telaga Cebong diasumsikan rata-rata menggunakan tenda berkapasitas empat orang dengan ukuran 2,5x2,5 m2 (dengan pembulatan). Salah satu aspek yang berpengaruh langsung terhadap wisatawan adalah aspek kenyamanan. Agar satu tenda dengan tenda lainnya terasa nyaman, maka jarak antara keduanya diatur sejauh 1 meter. Berdasarkan asumsi tersebut, didapatkan luas untuk mendirikan tenda kapasitas 4 orang secara nyaman yaitu 3,5 x 3,5 m2 (Gambar 6). Waktu yang disediakan oleh pengelola kawasan wisata untuk kegiatan wisata 
Tabel 1. Perhitungan PCC

\begin{tabular}{lrrrrr}
\hline \multicolumn{1}{c}{ Nama } & A (m2) & B (m2) & Rf & PCC (tenda/hari) & PCC (orang/hari) \\
\hline Blok 2 & 260,42 & 12,25 & 2,4 & 51 & 204 \\
Blok 3A & 850,61 & & & 167 & 668 \\
Blok 3B & 204,97 & & & 40 & 160 \\
Blok 1B & 381,82 & & 75 & 300 \\
Blok 1A & 362,90 & & 71 & 284 \\
Total & $2.060,72$ & Total & 404 & 1.615 \\
\hline
\end{tabular}

Sumber: Foto Udara dan Wawancara, 2017 (Diolah)

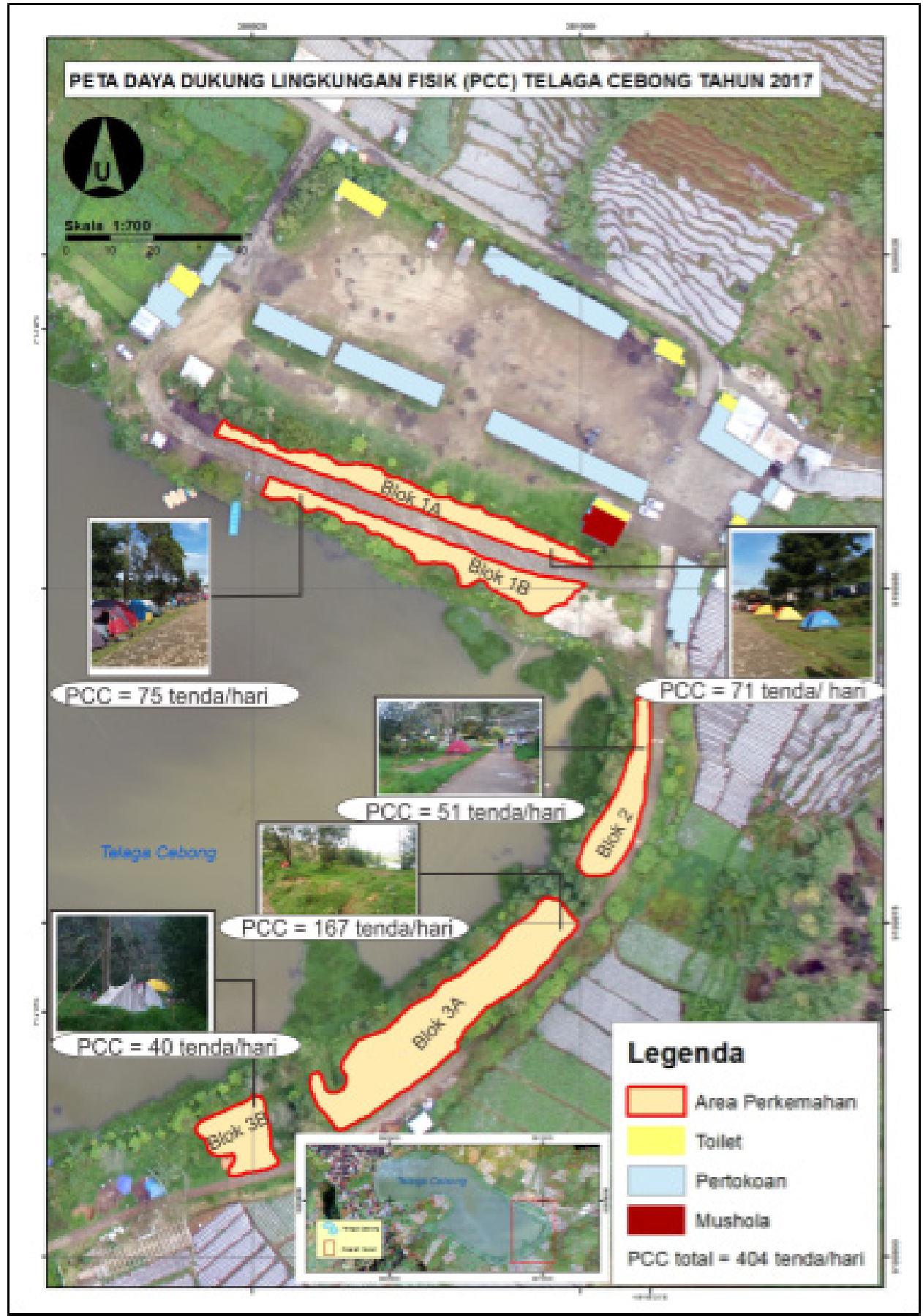

Gambar 7. Peta PCC Telaga Cebong (Pengolahan Foto Udara dan Perhitungan PCC, 2017) 
adalah 24 jam; sementara rata-rata durasi kunjungan oleh wisatawan yang berkemah adalah 10 jam, yaitu dari pukul 23.00 WIB hingga pagi hari pukul 09.00 WIB. Oleh sebab itu, faktor rotasi yang didapatkan adalah 2,4.

Daya dukung fisik (PCC) total kawasan perkemahan Telaga Cebong dalam satu hari adalah 404 tenda, sedangkan PCC total kawasan perkemahan Telaga Cebong dalam satu hari sebanyak 1.615 orang per hari (Tabel 1). Berdasarkan Peta PCC Telaga Cebong (Gambar 7) Blok 3A memiliki PCC terbesar yaitu mampu menampung 167 tenda perhari. Hal tersebut disebabkan Blok 3A memiliki area paling luas diantara blok yang lain. Nilai PCC yang dihasilkan tersebut menunjukkan daya tampung dari area perkemahan Telaga Cebong berdasarkan luas dari masing-masing blok. Segmentasi blok tersebut bertujuan untuk memberikan rekomendasi terhadap pelaku wisata di Telaga Cebong agar diatur jumlah tenda sesuai daya tampung masing-masing blok. Selain itu, jumlah tenda yang sesuai kapasitas dan penataan tenda yang baik bertujuan agar tidak mengurangi nilai estetika pemandangan ke Telaga Cebong baik bagi wisatawan yang berkemah maupun yang sekedar berkunjung untuk menikmati keindahan Telaga Cebong. Jumlah tenda wisatawan yang berkemah di Telaga Cebong adalah 66 tenda saat akhir pekan (Minggu, 5 November 2017), sedangkan jumlah rata-rata tenda saat hari kerja hanya 4 tenda (Senin-Rabu, 6-8 November 2017). Oleh sebab itu, jumlah pengunjung yang berkemah di sekitar Telaga Cebong baik saat hari kerja maupun saat akhir pekan belum melampaui daya dukung lingkungan fisik Telaga Cebong.

Rekomendasi Strategi Optimalisasi

Kawasan wisata Telaga Cebong merupakan salah satu multiplayer effect dari wisata Puncak Sikunir. Namun demikian,waktutinggalwisatawanhanyasebentarkarena setelah peristiwa matahari terbit (sunrise), wisatawan Telaga Cebong cenderung memberesi perkemahan mereka dan pergi dari Telaga Cebong. Oleh sebab itu, wisata berkemah di Telaga Cebong perlu dioptimalkan karena daya dukungnya dapat memuat 1.615 orang/ hari. Pengoptimalan wisata tersebut dapat dilakukan dengan melakukan perbaikan sarana prasarana, meningkatkan tingkat kebersihan, pengelolaan sampah yang baik, menambah variasi kuliner, dan penambahan kegiatan yang dapat memberikan daya tarik kepada pengunjung. Penambahan jumlah toilet dan peningkatan kenyamanan toilet menjadi hal utama yang harus diperhatikan. Selain itu, kenyamanan tempat ibadah (mushola) juga perlu ditingkatkan. Salah satu indikator pariwisata berkelanjutan menurut UNWTO (2001) yaitu environmental purity. Kondisi lingkungansangat diperhatikanuntukmenujupariwisata berkelanjutan. Lingkungan desa yang didukung sumberdaya alam khas menjadi potensi unggulan untuk dapat dikembangkan menuju pariwisata berkelanjutan di Desa Sembungan. Penataan ruang perlu dilakukan agar sektor pertanian dan pariwisata di Desa Sembungan dapat berjalan beriringan dan berkelanjutan. Daya tarik lain dari Telaga Cebong adalah kondisi udara pegunungan yang sejuk dan letaknya yang berada di tengah perbukitan. Menurut Zahra, dkk (2014) perpaduan komponen lingkungan seperti angin dan air memberikan kesannyaman dan sejuk pada suatu kawasan sehingga cocok dijadikan objek rekreasi dan objek untuk berfoto. Oleh karena itu, penambahan spot foto yang menarik juga perlu diperhatikan untuk menambah daya tarik objek Telaga Cebong. Atraksi wisata merupakan daya tari kalam, budaya, maupun buatan yang disebut sebagai minat khusus(Sunaryo, 2013) dalam (Nawangsari, Muryani, \& Utomowati, 2018). Atraksi wisata dengan menggabungkan unsur alami dan unsur buatan merupakan potensi wisata yang dapat dinikmati pengunjung agar tidak jenuh dalam berwisata di Kawasan Telaga Cebong. Selain pengembangan daya tarik utama berupa telaga, di pengembangan kawasan Telaga Cebong berupa atraksi danfasilitaswisatayaituflyingfox, boat, dan perahuuntuk mengelilingi telaga perlu pula untuk dikembangkan. Pendapat dari wisatawan terkait penambahan dan perbaikan fasilitas di Telaga Cebong dapat menjadi masukan bagi pemangku kebijakan dan Pokdarwis untuk mengevaluasi tata ruang baik yang sudah dijalankan maupun yang akan dibangun. Perbaikan maupun penambahan fasilitas, terutama sarana prasarana perlu dipertimbangkan secara matang agar dapat meningkatkan keuntungan tetapi tidak menurunkan kualitas lingkungan.

\section{KESIMPULAN}

Nilai daya dukung lingkungan fisik (PCC) di kawasan berkemah Telaga Cebong adalah 404 tenda per hari atau 1.615 orang per hari. Jumlah pengunjung yang berkemah di sekitar Telaga Cebong baik saat hari kerja maupun saat akhir pekan belum melampaui daya dukung lingkungan fisik Telaga Cebong. Oleh sebab itu, perlu strategi optimalisasi objek wisata Telaga Cebong berdasarkan asas pariwisata berkelanjutan, yaitu dengan melakukan perbaikan sarana prasarana, meningkatkan tingkat kebersihan, pengelolaan sampah yang baik, penambahan kegiatan yang dapat memberikan daya tarik kepada pengunjung, penataan ruang, penambahan tempat untuk berfoto, pengembangan atraksi wisata, dan pengembangan fasilitas wisata telaga, misalnya perahu, boat, serta flying fox.

\section{UCAPAN TERIMA KASIH}

Terima kasih kepada Departemen Geografi Lingkungan dan angkatan 2014 Blok 1 Geografi Lingkungan yang telah membantu pelaksanaan persiapan dan pengambilan data penelitian ini.

\section{DAFTAR PUSTAKA}

Detik. (2014). Selamat Datang di Sembungan, Desa Tertinggi di Pulau Jawa, Detik. Diakses tanggal 12 Agustus 2017 pukul 15:05 WIB, dari https://detik.com 
Damanik, Janianton, \& Weber, H. F. (2006). Perencanaan Ekowisata: Dari Teori ke Aplikasi. Yogyakarta: C.V Andi Offset.

Greymore, M. (2005). Journey to sustainability: small regions, sustainable carrying capcity and sustainability assessment methods. Disertasi, Australian School of Environmental Studies, Faculty of Environmental Sciences, Griffith University, Australia.

Gunn, C.A. (1994). Tourisme Planning Bassic. Concept. Casees London: Taylor dan Francis Ltd.

Fandeli, C. dan Muhammad. (2009). PrinsipPrinsip Dasar Mengkonservasi Landskap. Yogyakarta: Gadjah Mada University Press

Irhamna, S. A. (2017). Dampak Pengembangan Pariwisata Terhadap Perekonomian Masyarakat Sekitar Objek Wisata di Dieng Kabupaten Wonosobo. Economics Development Analysis Journal, Vol. 6 No. 3, hal: 320-327.

Machdalena, S., Dewi, A. P., \& Soemantri, Y. S. (2018). The Lodge Maribaya Sebagai Salah Satu Pilihan Destinasi Ekowisata Kabupaten Bandung Barat. Jurnal Pariwisata Terapan, 2(2), 96-107.

Muhamad. (2013). Kapasitas Daya Dukung Fisik dan Lingkungan Optimal sebagai Daya Dukung Kepariwisataan Alam Yogyakarta Utara Setelah Pascaerupsi Merapi 2010. KAWISTARA, 3(2), 117-226.

Nawangsari, D., Muryani, C., \& Utomowati, R. (2018). Pengembangan Wisata Pantai Desa Watu Karung dan Desa Sendang Kabupaten Pacitan Tahun 2017. Jurnal GeoEco, 4(1), 31-40.

Nizar, Muhammad Afdi. (2011). Pengaruh Pariwisata terhadap Pertumbuhan Ekonomi di Indonesia. Jurnal Kepariwisataan Indonesia Vol. 6 No. 2, Hal. 195 - 211.

Pamungkas, R.,D. (2017). Daya Dukung Wisata Alam Golden Sunrise dan Telaga Cebong di Kabupaten Wonosobo. Laporan Penelitian. Yogyakarta: Fakultas Kehutanan, Universitas Gadjah Mada. Pitana, I Gde. (2005). Sosiologi Pariwisata. Yogyakarta: Andi Offset Yogyakarta.

Purwanto, S., Syaufina, L., Gunawan, A. (2014). Kajian Potensi dan Daya Dukung Taman Wisata Alam Bukit Kelam untuk Strategi Pengembangan Ekowisata. Jurnal Pengelolaan Sumberdaya Alam dan Lingkungan vol. 4 no. 2 (Desember 2014): 119-125.

Raharja, D. T. (2012). Membangun Pariwisata Bersama Rakyat: Kajian Partisipasi Lokal Dalam Membangun Desa Wisata Di Dieng Plateau. Jurnal Kawistara, Vol. 2 No. 3, hal: 225-328.
Rani, Deddy Prasetya Maha. 2014. Pengembangan Potensi Pariwisata Kabupaten Sumenep, Madura, Jawa Timur (Studi Kasus: Pantai Lombang). Jurnal Politik Muda, Vol. 3 No. 3, Hal 412-421. Rees, J. (1990). Natural Resources: Allocation, Economics and Policy. London: Routledge. Rinaldi, O. (2015). Kawasan Bumi Perkemahan di Kota Singkawang. Jurnal Online Mahasiswa Arsitektur Universitas Tanjungpura, 3(2), 198-210.

Soehadha, M. (2013). Ritual Rambut Gembel Dalam Arus Ekspansi Pasar Pariwisata. Jurnal Walisongo, Vol. 21(2), hal 347-364. Soemarwoto, O. (2004). Ekologi, Lingkungan Hidup dan Pembangunan Edisi ke 10. Jakarta: Penerbit Djambatan. Sudarmadji., Supriyono, H., Lestari, S. (2015). DanauDanau Volkanik di Dataran Tinggi Dieng: Pemanfaatan dan Masalah Lingkungan yang Dihadapi. Jurnal Teknosains. Vol. 5 No. 1: 36-48. Sunaryo, B. (2013). Kebijakan Pembangunan Destinasi Pariwisata: Konsep dan aplikasinya di Indonesia. Yogyakarta: Gava Media.

Susilawati, Mustoyo, Budhisurya, E., Anggono, R. C. W., Simanjuntak, B. H. (2013). Analisis Kesuburan Tanah dengan Indikator Mikroorganisme Tanah pada Berbagai Sistem Penggunaan Lahan di Plateau Dieng. Jurnal Agric, Vol. 25 No. 1, hal: 64-72.

Tribun. (2017). Pengunjung Sikunir Berjubel Begini, Pemilik Homestay Kehabisan Kamar, Tribun. Diakses diakses tanggal 14 September 2017 pukul 17:25 WIB dari www.jateng.tribunnews.com

UNWTO. (2001). The Concept of Sustainable Tourism. Diakses tanggal 30 November 2017 pukul 12.30 WIB dari http://www.worldtourism.org/sustainable/concept.htm

UNWTO. (2013). UNWTO Tourism Highlight 2013 Edition. UNWTO

Yulianda, Fredinan. (2007). Ekowisata Bahari sebagai Alternatif Pemanfaatan Sumberdaya Pesisir Berbasis Konservasi. Disampaikan pada Seminar Sain pada Departemen MSP, FPIK IPB, 21 Februari 2007.

Zahra, A. F., Sitawati, \& Suryanto, A. (2014). Evaluasi Keindahan Dan Kenyamanan Ruang Terbuka Hijau ( RTH ) AlunAlun Kota Batu. Jurnal Produksi Tanaman, 2(7), 524-532. 